\title{
ENHANCING THE CULTURAL TOURISM EXPERIENCE: THE CASE OF HISTORICAL OLD JEDDAH
}

\author{
GHADEER ALAWI, HATOON JAMJOUM \& HAITHAM SAMIR \\ College of Architecture and Design, Effat University, Saudi Arabia
}

\begin{abstract}
The Historical Old Jeddah, otherwise called Al-Balad, was inscribed in the UNESCO world heritage list in 2014. Since then, the international recognition has strengthened its appeal as a heritage tourism destination, and the need for a promising heritage tourism plan has become essential. Many researchers intended to develop heritage tourism plans from a decision maker's perspective, but few studies have explored heritage resources from tourists' perspective. The objective of this study is to evaluate tourists' experience of and satisfaction with the Al-Balad heritage site. The study defines factors which influence their experience such as presented information; comfort and safety; cultural values; and entertainment experiences. A field study and a structured survey are conducted in order to analyze the quality of the tourists' experience. The research, by utilizing the information gathered in this survey, concludes with considerations to be incorporated into the tourism plan of the old city. The outcome of this research shall contribute to the Saudi 2030 vision of enabling and enhancing the development of tourism sector and promoting the Islamic, Arab and National heritage of the Kingdom.

Keywords: urban heritage, cultural tourism, tourist experience, Old Jeddah.
\end{abstract}

\section{INTRODUCTION}

Cultural and heritage became an essential element of the tourism industry. Cultural tourism is considered as one of the fastest growing segments of global tourism. However, cultural tourism market is increasingly competitive, and cultural attractions must fight for a share within this market [1]. Many cities compete in producing and promoting themselves for cultural and heritage tourism; thus, the need for effective heritage tourism implementation plan in Saudi Arabia is essential. Al-Balad is the old historic center of the City of Jeddah. In 2014, it was inscribed in the UNESCO world heritage list [2]. This international recognition has strengthened its appeal as a heritage tourism destination. To be able to compete, the tourism plan of Old Jeddah must implement principles to enhance the tourists'/visitors' experience quality, which is the main factor of successful cultural tourism. Many types of research intended to develop heritage tourism plans from a decision-maker's perspective, but few studies have explored heritage resources from tourists' perspective. Providing a pleasing tourist experience is crucial for heritage long-term success and sustainability.

\section{OBJECTIVES AND METHODOLOGY}

The main goal of this study is to set, investigate, and identify applicable tools and strategies that could provide a pleasing experience for tourists in Old Jeddah. The outcome should contribute to the Saudi 2030 Vision by enabling and enhancing the development of tourism sector in KSA to compete internationally as well as by promoting the Islamic, Arab and National heritage of the Kingdom.

To achieve this goal, the objectives of this study can be summarized as follow: first, to identify the major various factors affecting the tourists' experience. Second, to evaluate tourist'/visitors' experience and satisfaction of Al-Balad heritage site considering the different identified factors. Third, to conclude sustainable principles that promote the city heritage, focusing on tourists'/visitors' experience quality. These principles are to be incorporated into the tourism plan of Saudi Arabian heritage. In order to achieve the outlined 
objectives of this paper, this research applies a qualitative strategy based on the following three steps:

a) Literature review: the theoretical framework illustrates the review of the literature as the basis of this study. The scope of the research deals with the tangible and intangible elements of heritage sites that directly affect the visitors' experience.

b) Conducting data: a structured questionnaire survey based on selected criteria distributed among local visitors and tourists. This part focuses on understanding the current quality of tourist's experience, their preferences, and their level of satisfaction regarding the current conditions. This part conducts data needed that are not available from other resources, such as the behavior, character, opinion, and knowledge. This approach allows planners to obtain qualitative results and to address a bottom-up approach. This increases the emphasis on representative citizen participation, who are usually not consulted in planning issues.

c) Site evaluation: based on both, the theoretical background and the data obtained from the fieldwork, the current built environment of Old Jeddah is assessed and analyzed. The research further provides a set of recommendations to improve the current conditions.

\section{HERITAGE TOURISM}

In the late 1980s and early 1990s, heritage tourism gained increasing attention, with a growing body of specific literature being devoted to this topic [3]. Fyall and Garrod (1998) define heritage tourism as an economic activity that makes use of sociocultural assets to attract visitors [4]. Thus, heritage tourism is a mixture of many aspects. Heritage tourism is a part of the global tourism that is oriented towards the cultural heritage component of a location where tourism is active. The National Trust for Historic Preservation in the United States defines heritage tourism as "traveling to experience the places and activities that authentically represent the stories and people of the past".

According to Hall (1990), heritage tourism is a subset of cultural ethnic and educational forms of special interest of tourism [5]. This includes many aspects of touristic behavior ranging from an examination of the physical remains of the past to the experience of contemporary cultural traditions. Hollinshead (1988) asserts that heritage tourism also includes local cultural traditions; the community heritage that serves as touristic attractions and embraces folkloric traditions, arts and crafts, ethnic history, social customs and cultural celebrations [6]. In fact, heritage tourism is representative of many contemporary travelers' desire to directly experience and consume diverse past and present cultural landscapes, environments, and places. As heritage tourism becomes an increasingly crucial factor for tourist destinations, it is important to assess how heritage tourists can be better understood and serviced through marketing, planning, and programming with local and regional communities [7].

Cultural attractions play a key role in tourism at all levels, from the global highlights of world culture to attractions that underpin local identities [1]. Cultural heritage tourism is significant for several reasons: it has a positive economic and social impact; it establishes and reinforces identity; it helps preserve the cultural heritage; with culture as an instrument, it facilitates harmony and understanding among people; and it supports culture and helps renew tourism [1].

A study by the Travel Industry Association in 2003 shows that heritage travelers stay longer at their destinations and spend more money there than other types of travelers. Heritage tourism creates jobs, new business opportunities, and strengthens local economies. It protects natural and cultural resources, which improve the quality of life for residents and travelers who participate in the services and attractions. It also promotes community pride by 
allowing people to work together to enhance economic and cultural development through distinct community opportunities. Studies show that travelers are more opt to visit places with a strong community identity.

\section{FACTORS AFFECTING TOURISM EXPERIENCE}

Visitors' experience plays a critical role in the conceptualization of heritage tourism. In his study [8], argues that heritage tourism industry had shifted from a product-focused orientation toward a customer-focused orientation. Visitors are considered as the customers and their needs must be responded accordingly to maximize satisfaction and loyalty. The marketing concept emphasizes on satisfying customers' needs, through the integrated efforts of all functional elements to enhance the organization's performance [9]. This approach is one of the most effective methods that can effectively impact the performance of cultural heritage destinations such Old Jeddah.

McKercher and Wong (2004) indicate that most heritage management focuses on developing the physical features of the heritage location without taking into consideration the visitor experience [10]. Weiler and $\mathrm{Yu}(2008)$ argue that the visitor experience is expected to be richer and more memorable when attention is not limited to physical access but also the opportunities to understand, appreciate, and interact [11]. Scholars in this field have identified many critical heritage attributes to promote satisfying tourist experience.

Pizam et al. (1978) is one of the pioneer researchers who proposed dimensions of tourist satisfaction [12]. He argues that evaluation should be based on identifying and measuring the dimensions of destination performance [13]. The perception of each of the attributes could lead to satisfaction or dissatisfaction with the overall visiting experience.

\subsection{Tourist services and facilities}

Tourism is essentially a service industry and it is highly service driven. Tourism provides products and services for people participating in activities at places other than their residence [9]. Service is an act or performance that one party can offer to another that is essentially intangible and may not result in ownership of a physical product [14]. The service aspects of heritage tourism should cover the whole visitor's experience. Providing memorable experience and maximizing customer satisfaction should be at every stage in the tourist value chain [15].

For the tourist experience to be pleasant and comfortable, two criteria should be taken into account: First is the availability of basic facilities needed such as information facilities, restrooms, signage, parking areas and routes. Second is maintenance and perfect state of these facilities. Welcome, and information facilities are the basic elements to provide confidence to the visitors as they receive information to prevent them from being lost [16]. Walkways and coherent routs are relevant facilities visitors use to move from a point to another. Visitation routs layout and design influence the visitors' experience. It is preferable to separate walking paths from other multi-use routes such as cyclists, horse riders, joggers, and pet walkers as they may cause discomfort for visitors [16].

Other suitable facilities are the ones supporting educational purposes and providing intelligent information to heritage such as interpretation centers. They provide information of activities, actions, and programs that set up the recreational experience. This development is supported by on-site facilities and trained staff. Beside the information facilities, basic services in cultural heritage area should include cleaning, maintaining, waste management, and first aids. If these services are offered with well-trained guides-interpreters, the intellectual experience of the site can be guaranteed [16]. 


\subsection{Hospitality}

Hospitality services are an essential component of tourist experience; it refers to two types of services: accommodation (the provision of overnight accommodation for people traveling away from home) and food and beverage (the provision of options for people dining outside their home). Heritage areas should provide a variety of quality accommodation within walking distance from the heritage destination such as hotels, motels, and hotel apartments. These accommodations should be comfortable, clean, and safe. It should protect tourists from risks and accidents that may occur. Food and beverage services, according to Statistics Canada, comprises of "establishments primarily engaged in preparing meals, snacks, and beverages, to customer order, for immediate consumption on and off the premises" [17]. This includes restaurants, cafes, and food market. Local restaurants should provide a variety of traditional dishes where tourist can not only enjoy the delicious food but also can learn the food culture and journey. Hotel restaurants are also open to the public.

\subsection{Recreational and cultural activities}

Recreation and cultural activities can highly contribute to the enhancement of tourism experience through cultural programs, activities, and events. History is not tangible but presents events that happened in the past. Tourists do not only travel to visit physical objects but also to encounter experiences that link them with this history. These experiences include festivals, shows, theaters, live art, live music and dance performances, social activities, tribal events, cultural events, and many other related professional activities [18]. London provides a good example of heritage attraction activities. For instance, the Tower of London, a historic castle located on the north bank of the River Thames in central London, launched an interactive exhibition named "Hands on History", that encourages children and adults to explore the history of arms and armor [19]. A further generator of interest in the castles is the increasing involvement in the summer music performances, picnic on the lawn, and fullyfledged festivals. Galleries and exhibitions have also contributed to the number of visitors in London Castle by improving their experience with populist exhibitions and displays [19].

\subsection{Technological services}

Technology can also enhance cultural tourist's experience. The Internet has reshaped the traditional means of information and communication. These changes mean that information sharing, interaction and collaboration became the driving force for digital citizens. Technologies such as web sites, social media, and smartphone applications are powerful and effortless in its usability yet greatly influence the user's experience and satisfaction [20]. Today, culture is centered around digital information; thus, digital resilience is needed in heritage tourism experience. The "Internet of things" will eventually penetrate every physical objects, activities, and context. Technologies can mature, store, and process information digitally at an exponential rate. Some examples of these technologies are computers, smartphones, 2D image scanners, 3D laser scanners, audio recorders, as well as HD digital camcorders with features such as panoramic, stereoscopic 3D [21]. These technologies allow remote access to heritage sites at any given space and time and assist tourists with necessary information.

Digital services can enhance tourist experience in three stages: before the visit, during the visit, and after the visit. Prior to the visit, tourists use web browsing for planning and preparing their trips, reading reviews, and accessing information related to the site of interest 
[20]. During the visit, tourist use variety of technologies in the entirety of the journey. For example, mobile location-based applications such as GPS provide access to the information and services within the vicinity of the tourist. This allows the tourist to discover places of interest on location. During their visit, tourist can also access information services related to the site, sculptures, architecture, and other physical elements [20]. After the visit, tourists share a set of digital photos through social media such as Facebook, Instagram, and YouTube allowing immediate access by peers to users' whereabouts and their experiences.

\subsection{Safety}

Providing high-quality tourism experiences must account for the principles of safety and security, becoming a very important aspect of any tourism destinations. Crime Prevention Through Environmental Design, CPTED, is a multi-disciplinary approach to prevent criminal behavior through environmental design. It depends on the idea that suitable design and efficient use of the built environment can cause a decrease in the incidence and fear of crime, and an increase in safety, security, and quality of life [22].

CPTED provides guidelines that were prepared by the City of Virginia Beach's CPTED Committee to be used as a tool for planners and design professionals to build a "Quality Physical Environment", and to study the site design to create safer designs in new and existing developments. There are four main principles of CPTED: natural surveillance, natural access control, territorial reinforcement, and maintenance and management. Many planning and design strategies can be translated from the four CPTED principles including the allowing for clear sight lines; providing adequate lighting; minimizing concealed and isolated routes; avoiding entrapment; reducing isolation; using of activity generators; creating a sense of ownership through maintenance and management; providing signs and information; and improving overall design of the built environment [23].

\subsection{Accessibility}

Darcy and Dickson (2009) define accessible tourism as tourism that enables people with access requirements, including mobility, vision, hearing and cognitive dimensions of access, to function independently and with equity and dignity through the delivery of universally designed tourism products, services, and environments [24]. This definition is inclusive of all people including those traveling with children in prams, people with disabilities and seniors. In short, it is a process of enabling people of all abilities to enjoy an experience independently and with equity and dignity through the delivery of tourism services. Accessibility in tourism can take different forms:

a) Physical accessibility such as transportation, accommodation, and attraction.

b) Attitudinal barrier which is the tour operators and city planners ${ }^{\text {ee }}$ attitude towards the disabled segment of the tourism group.

c) Accessible information provided to the disabled people about the accessibility of the destination being advertised.

Tourism industries should provide an accessible tourism education for their staff to be able to provide reliable information for the disabled tourist before or during their trip. According to ENAT, the European Network for Accessible Tourism, accessible tourism includes:

a) Barrier-free destinations: infrastructure and facilities.

b) Transport: by air, land, and sea, suitable for all users. 
To ensure that accessible tourism is developed in a sustainable manner, it requires that tourist destinations must adopt the principle of universal design and to ensure that all persons, regardless of their physical or cognitive needs, are able to use and enjoy the available amenities in an equitable and sustainable manner.

\section{OLD JEDDAH - AL-BALAD}

The Historical Old Jeddah or what is called the downtown Jeddah is located in the heart of present Jeddah [25] (Figs 1 and 2). Its existence dates back to the era before Islam. In the year $26 \mathrm{H}, 647 \mathrm{CE}$, the turning point in the history of Al-Balad came during the Caliph Uthman ibn Affan. He located the area as a seaport of the Holy City Makkah facilitating regional commerce as well as receiving Hajj and Umrah pilgrims [26]. Al-Balad includes a number of heritage buildings and monuments such as the Old Jeddah wall and its historical open squares [25]. There are a number of historic mosques within Old Jeddah, the most important among them are Uthman Ibn Affan mosque, Al Pasha mosque, Al Shafi'i mosque, Al Memar mosque, Akash mosque, and Al Hanafi mosque [26].

\subsection{The old wall}

The old wall and its historic gate are one of the most important features of Al-Balad. This ancient wall was built with the active participation of the local population during Mamluk prince, Hussain Al Kurdi campaign against Portuguese. He wanted to fortify the city from attacks from the Red Sea. The wall fortified with a fort, towers, and cannons to repel the attacking vessels. It is surrounded by a deep mote for additional fortification [26]. The Old Jeddah wall has two main doors, one facing the Holy Makkah, and the other facing the sea. It also includes six towers; each is about six cubits in diameter. The wall also has six additional doors: Bab Makkah, Bab Al Madina, Bab Al-Sharif, Bab Jadeed, Bab Al Bint, and $\mathrm{Bab} \mathrm{Al}$ Mughrabi. At the beginning of 20th century, a large part of the wall was replaced due to modern urbanization [26].

\subsection{Jeddah historical area}

The old wall of Jeddah functions as an entrance to the entire area, which is divided into several neighborhoods [26]. These neighborhoods have gained their specific names based on

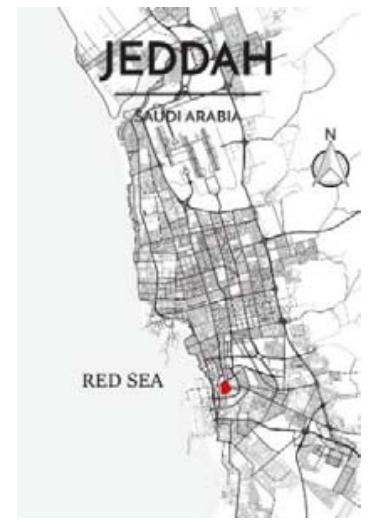

Figure 1: Historic Jeddah (AlBalad) [27].

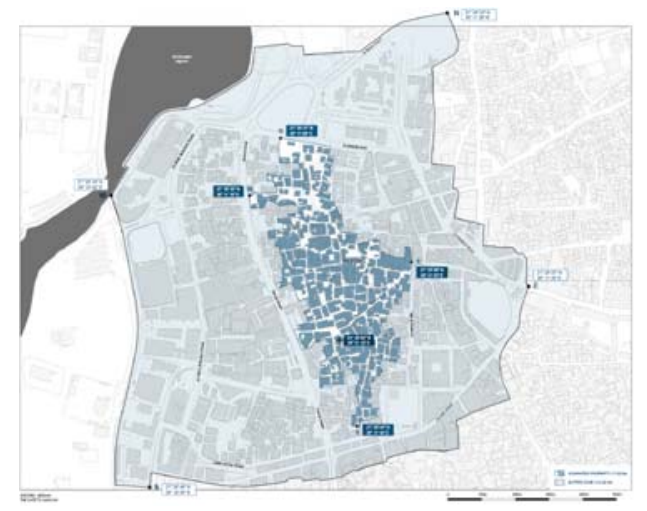

Figure 2: Historic Jeddah nominated property and buffer zone [28]. 
their geographical location within the city or for some famous events they have occurred such as the following:

a) Haret Al Mazloom: it was named after Abdul Kareem Al Barzanji death, who was oppressed and killed by the Ottoman ruler of his time.

b) Haret Al Yemin: located in the southern part of Al Alawi Street inside the wall. It was named so because of its direction facing Yemen. It includes Dar Nasif, Dar Jamjoum, Dar Al Shaarawi and Dar Al Samad.

c) Haret Al Bahr: located in the southwestern part of old Jeddah, overlooking the Red Sea.

d) Haret Al million Tifl: located south of Jeddah and so named because of the large presence of children in the alleys of this neighborhood [26].

\subsection{Historical Jeddah houses}

Local residents built houses using rectified stones, which were found in the adjacent $\mathrm{Al}$ Arbaeen Lake then it was shaped manually with hand-tools and placed according to their sizes, separated by wooden planks [25]. They also used clay, which was used for bonding the stones and compacting them into building blocks. The old buildings were large and similar to the modern concrete buildings. They are mainly made out of wooden structures to alleviate the effects of desert climate. The height of some of these buildings reached more than thirty meters. Many of these buildings are still durable and remain in good condition even after the passage of several decades [25].

\subsection{Historical Jeddah souq}

The souk area is around 1.5 square kilometers. It still presents traditional life with socioeconomic nature. This area is currently concentrated around the mosques and markets where there are some traditional craft-shops. The most famous markets include Souk Al Alawi, Souk Al Baddu, Souk Gabil, and ouk Al Nada [26]. In the 1970s, the municipality of Jeddah began historical preservation efforts. The municipality of Jeddah founded the Jeddah Historical Preservation Society to preserve the historical architecture and cultural heritage of Al-Balad. In 1990, the Historical Area Preservation Department was established aiming to promote cultural tourism in the country. In 2002, the United States embarked \$4 million for the preservation society. By 2009, it was nominated by Saudi Commission for Tourism and Antiquities to be listed in UNESCO's World Heritage site and it was accepted on 2014 [25].

\section{RESEARCH SURVEY}

This survey took place in December 2017. The media for this survey was both electronic and direct interview. The total number of participants is 51 persons. The survey consists of 17 questions serving the following goals:

a) The first four questions are introductory questions to investigate preliminary data and responder's general profile such as gender, age, nationality, and education.

b) Questions 5,6 and 7 are multiple-choice based questions to identify general information related to visiting Jeddah Al-Balad such as the purpose, the number of visits as well preferable visiting time.

c) Questions 8-14 are rating based questions to assess participant level of satisfaction with the qualities conducted from the analytical literature review including the following: services and facilities, hospitality, recreational and cultural activity, technology, safety, accessibility. 
d) Questions 14, 15 and 16 are rating based questions to evaluate participation satisfaction with the overall visiting experience.

e) The last question is an open answer question to provide suggestions, needs, and preference to improve future visitation to the area.

\section{DISCUSSION}

\subsection{Respondents' general information}

The survey results showed that most of the participants are female $(82 \%)$ while males are only (18\%). From all participants, more than half of the participants (75\%) are in age $20-30$, $(16 \%)$ are in age $31-40$, and only $(8 \%)$ is above 40 . This almost represents the normal age distribution in Saudi Arabia. Most of the sample are Saudi (90\%) while only (10\%) are nonSaudi which represent the perspective of the internal tourist. This stresses on the importance of the potential to develop Al-Balad as an international tourism distention, not only for local tourism.

The sample included a majority of (75\%) holding a bachelor's degree, $(12 \%)$ holding a high school certificate, $(8 \%)$ and $(4 \%)$ holding master and $\mathrm{PhD}$ degree, respectively. This also represents the average educational level of Saudi citizens. According to participants (78\%) visit Al-Balad for tourism and entertainment, (27\%) for shopping, (22\%) for education, while only $(6 \%)$ for business. Tourism and entertainment recorded the highest purpose of visiting the site, which reflects the appreciation of space historical values as well as the experience associated with the visit. (41\%) visited Al-Balad more than three times within the past two years, $(37 \%)$ visited the site twice, while $(22 \%)$ visited it once. This measures the importance of enhancing visitors experience in order to increase the visiting rate.

According to participants, (43\%) prefers visiting Al-Balad in the evening, (41\%) favors the visit at night, while only (16\%) prefer to visit the site in the mornings. This can be a reflection of the weather condition in Jeddah most of the year, especially in the mornings.

\subsection{Satisfaction with services and facilities}

Visitor's satisfaction with the existing services and facilities scored a low rate, an average of $(2.4 / 5)$. To analyze this score, satisfaction with the restroom cleanness scored the lowest rate in this section (1.75/5), followed by the availability of parking (1.94/5). Also, visitors are unsatisfied with the quality of walkways and pedestrians' pathways as it scored (2.65/5) and they are also unsatisfied with the availability of general information regarding the site and monuments such as brochures, tourist guide, signs, and graphics as it scored (2.9/5). Overall,

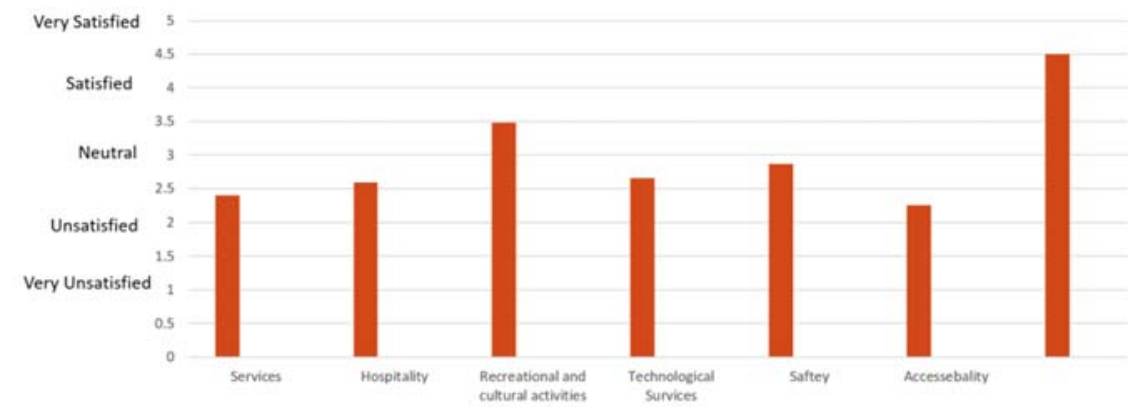

Figure 3: Overall visitors' satisfaction experience at Al-Balad. 
visitors are unsatisfied with the available services and facilities. This emphasizes the importance of improving the existing facilities and the continuous maintenance.

\subsection{Satisfaction with hospitality}

Visitors' satisfaction with hospitality services including accommodation and food services is also low, scored an average of (2.59/5). To analyze this rating, visitors are unsatisfied with the availability of different hotels $(2.31 / 5)$, hotel cleanness $(2.39 / 5)$, food and snacks quality $(2.92 / 5)$, and food and beverage services $(2.94 / 5)$. Overall, visitors are unsatisfied with hospitality services within the area. This emphasizes the importance on the investment of accommodation and food services as they considered as the core of the tourism experience.

\subsection{Satisfaction with recreational and cultural activities}

Unlike the previous points, visitors are satisfied with the current recreational and cultural activities. This section scored an above average rate of (3.48/5). To analyze this rate, historic Jeddah festival scored the highest satisfaction rate (3.82/5) (Fig. 5), followed by the variety of events such as live art, music and dance performance (3.35), and finally the availability of cultural galleries, exhibitions, and museums (3.25/5). This highlights the current local efforts on creating a pleasant experience through activities. This also emphasizes the importance on improving and increasing the number of events and cultural activities.

\subsection{Satisfaction with the use of technology}

Visitors are unsatisfied with available technology incorporated with the site. This point scored a low rating of (2.65/5). Visitors are almost satisfied with the availability of information and services through digital technologies such as web browser, mobile application, and social media, it scored (2.84/5). However, they are unsatisfied with the availability of different technologies that enhances their experience such as $2 \mathrm{D}$ image scanner, audio recorder and panoramic screen; it scored (2.45/5). This highlights the potential of incorporating different technological tools within the site, which will ease and enhance their experience.

\subsection{Satisfaction with safety}

Furthermore, visitors are almost satisfied with the safety during their visit. This section scored $(2.89 / 5)$. To analyze this section, they are satisfied with the level of safety from crime and theft $(3.08 / 5)$ as well as with the amount of lighting within walkways and pedestrian
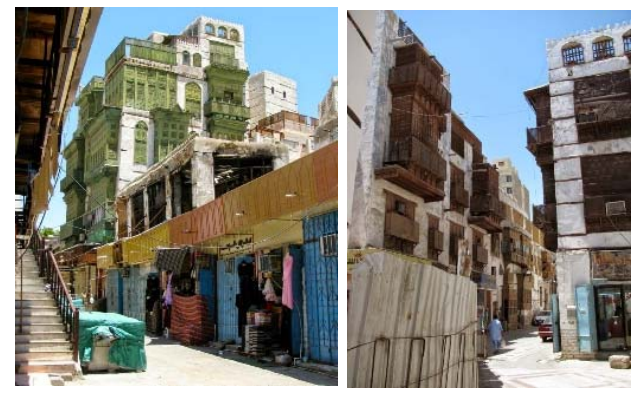

Figure 4: Old Jeddah houses [29].
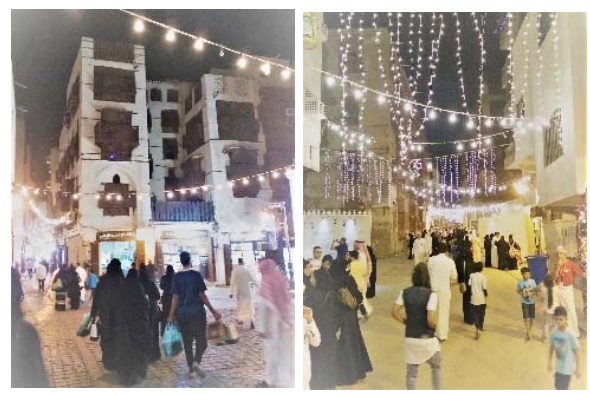

Figure 5: Historic Jeddah festival. (By Authors.) 
paths $(3.27 / 5)$. On the other hand, they are unsatisfied with the availability of clear and easy signage to follow escape routes in case of accidents such as fire (2.24/5). This illustrated a below average level of safety. More efforts are needed to emphasize this point, as it is capable to significantly decrease the amount of tourism within the site.

\subsection{Satisfaction with accessibility}

On the other hand, visitors are unsatisfied with site accessibility; this section scored (2.25/5). The satisfaction with the services provided for people with different disabilities scored the lowest rate $(1.98 / 5)$, followed by the availability of public transportation such as buses and taxies $(2.33 / 5)$. Clear and reachable routes also scored low rate of (2.43/5). Overall, physical accessibility needs to be improved within the site.

\subsection{Satisfaction with overall cleanness and maintenance}

Visitors are Fairley satisfied with the level of cleanness and maintenance. They voted a rate of $(2.45 / 5)$. overall cleanness of the site scored $(2.45 / 5)$ and the overall maintenance $(2.45 / 5)$. More financial budgets should be directed to cleanness and maintenance through employment or other methods.

\subsection{Overall experience rating}

Finally, visitors are satisfied with their overall experience during their visit to Al-Balad. They rated to their overall experience as (3.29/5). Significantly, (88\%) would recommend Jeddah Al-Balad as a touristic destination. This stresses the potential of having Al-Balad as an international tourism destination by enhancing many essential missing elements within the site.

\subsection{Suggestions}

Participants suggested some other key aspects if added and promoted it could enhance the overall experience of the visitors and consequently lead to an increase in the visitation rate. Aspects suggested included clean shops; traditional costumes; souvenir shops; cleanness of the place; diverse activities; pedestrian routes within the interior streets; methods to decrease traffic and people crowding; more parking areas; conservation of old buildings; using technology for tourism marketing; as well as providing more signage and graphics.

\section{CONCLUSION}

This study contributes a redefinition of planning considerations for cultural tourism in old Jeddah, Al-Balad, throughout an investigation of the visitors' experience and preferences. It highlights the most significant attributes of visitors' experience: services and facilities, hospitality, recreational and cultural activities, technology, safety, and accessibility. It is suggested that if the conditions for a quality visitation experience of the cultural assets of Old Jeddah are not assured, the enormous investments in the revitalization and safeguarding the site may be wasted. To have tourist potential based on the existing monuments, unique sights, and local attractions, is not sufficient for Al-Balad to establish itself as a tourist destination. Attempts at promoting this potential without paying attention to other components related to hospitality and users' satisfaction will lead to unsustainability.

However, the conducted survey analysis shows that tourists/visitors are satisfied with the current cultural activities and fairly satisfied with the safety and maintenance of the site. In 
contrast, the analysis underscores the available services and facilities; hospitality services; use of technology; as well as the quality level of accessibility. To deal with these problems, Jeddah has to plan for tourism development paying due attention to those elements that radically contribute to its urban attractiveness. The various elements that contribute to the tourist satisfaction and the enhancement of their experience have to be systemized and managed.

Thus, what seems to be needed is an integrated strategy that involves the government agencies and other stakeholders not only to intervene in the conservation and safeguarding of the physical fabric of Al-Balad but also to effectively work in providing a user-friendly site. For instance, using the opportunities offered by new technologies, providing better accessibility inclusive of all people including people with disabilities and elders, enhancing public transportation around the site connecting it to the entire city. In regard to services and facilities, the presence and quality of secondary or complementary tourist services such as hotels, restaurants, cafes, and exhibition halls have to be sufficiently provided and diversified to be attractive. Although Al-Balad hosts a number of cultural events of local and regional appeal such as the annual historic Jeddah festival, it is recommended to plan for other different events during the year such as live art, music, cultural dances etc.

In summation, a sustainable heritage tourism in Al-Balad has to be shifted from the ongoing product-focused orientation toward a customer-focused orientation by counting for the customers and their needs and accordingly maximizing satisfaction and loyalty.

\section{REFERENCES}

[1] Richards, G., Production and consumption of European cultural tourism. Annals of Tourism Research, 23(2), pp. 261-283, 1996.

[2] UNESCO (2014), Historic Jeddah, the Gate to Makkah, Online. http://whc.unesco.org/en/list/1361. Accessed on: 17 Dec. 2017.

[3] Balcar, M.J. \& Pearce, D.G., Heritage tourism on the west coast of New Zealand. Tourism Management, 17(3), pp. 203-212, 1996.

[4] Fyall, A. \& Garrod, B., Heritage tourism: at what price? Managing Leisure, 3(4), pp. 213-228, 1998.

[5] Hall, S., Cultural identity and diaspora. Identity: Community, Culture Difference, ed. J. Rutherford, Lawrence and Wishart: London, pp. 222-237, 1990.

[6] Hollinshead, K., First-blush of the longtime: the market development of Australia's living Aboriginal heritage. A paper composed of recognition of Australia's Bicentenary: 1988. In Tourism research: expanding boundaries. Proceedings of Travel and Tourism Research Association Nineteenth Annual Conference, Montreal, Canada, 19-23 Jun. 1988, Bureau of Economic and Business Research, University of Utah, pp. 183-198, 1988.

[7] O'Leary, J.T., Morrison, A.M. \& Alzua, A., Cultural and heritage tourism: Identifying niches for international travelers. Journal of Tourism Studies, 9(2), p. 2, 1998.

[8] Apostolakis, A., The convergence process in heritage tourism. Annals of Tourism Research, 30(4), pp. 795-812, 2003.

[9] Voon, B.H. \& Lee, N., Identifying dimensions of tourist satisfaction for a cultural destination: the case of longhouses in Sarawak (Borneo). International Journal of Business and Society, 10(2), p. 65, 2009.

[10] McKercher, B. \& Wong, D.Y., Understanding tourism behavior: Examining the combined effects of prior visitation history and destination status. Journal of Travel Research, 43(2), pp. 171-179, 2004. 
[11] Weiler, B. \& Yu, X., Case studies of the experiences of Chinese visitors to three tourist attractions in Victoria, Australia. Annals of Leisure Research, 11(1-2), pp. 225-241, 2008.

[12] Pizam, A., Neumann, Y. \& Reichel, A., Dimensions of tourist satisfaction with a destination area. Annals of Tourism Research, 5(3), pp. 314-322, 1978.

[13] Yao, Y., Assessing Tourist Experience Satisfaction with a Heritage Destination, 2013.

[14] Kotler, P., Marketing Management, the Millennium Edition, Prentice-Hall International, Inc.: New Jersey, p. 14, 2000.

[15] Yllmaz, Y. \& Bititci, U.S., Performance measurement in tourism: a value chain model. International Journal of Contemporary Hospitality Management, 18(4), pp. 341-349, 2006.

[16] Jose Vinals, M., Morant, M. \& Teruel, L., Psychological comfort and tourism experience. The Valencian natural protected areas (Spain) case study. Boletin De La Asociacion De Geografos Espanoles, 65, pp. 293-316, 2014.

[17] Westcott, M., Introduction to tourism and hospitality in BC, B.O.T. Project, BCcampus, BCcampus Open Textbooks \& BC Open Textbooks, 2014.

[18] Mwaipopo, L.J. \& Salim, I.S., Exploring destination branding through utilizing the capital inherent in a culture: The case of Zanzibar. Challenges in tourism development and sustainability. Proceedings of the International Conference Zanzibar, Tanzania, 2015.

[19] Liu, Y.D. \& Lin, C.F., The development of cultural tourism: A review of UK experience. Tourismos, 6(2), 2011.

[20] Ch'ng, E., Digital heritage tourism: Reconfiguring the visitor experience in heritage sites, museums and architecture in the era of pervasive computing. Proceedings of the Percorsi creative di turismo urbano (Creative Paths of Urban Tourism) Conference, pp. 22-24, 2011.

[21] Reino, S., Mitsche, N. \& Frew, A.J., The contribution of technology-based heritage interpretation to the visitor satisfaction in museums. Information and Communication Technologies in Tourism 2007, pp. 341-352, 2007.

[22] Clarke, R.V., Theoretical background to crime prevention through environmental design (CPTED) and situational prevention. Designing Out Crime: The Conference Papers, pp. 13-20, 1989.

[23] Cozens, P.M., Saville, G. \& Hillier, D., Crime prevention through environmental design (CPTED): a review and modern bibliography. Property management, 23(5), pp. 328-356, 2005.

[24] Darcy, S. \& Dickson, T.J., A whole-of-life approach to tourism: The case for accessible tourism experiences. Journal of Hospitality and Tourism Management, 16(1), pp. 32-44, 2009.

[25] http://whc.unesco.org/en/list/1361. Accessed on: Jan. 2018.

[26] https://www.scta.gov.sa/en/Antiquities-Museums/InternationallyRegisteredSites/ Pages/OldJeddah.aspx. Accessed on: Mar. 2018

[27] https://www.pointtwomaps.com/products/jeddah-city-map?utm_campaign=Pinterest $\% 20$ Buy\%20Button\&utm_medium=Social\&utm_source=Pinterest\&utm_content=pi

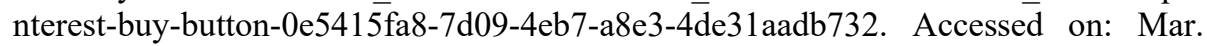
2018.

[28] http://whc.unesco.org/en/list/1361/multiple=1\&unique_number=1968. Accessed on: Mar. 2018.

[29] http://www.minorsights.com/2014/09/saudi-arabia-coral-houses-of-jeddahs.html ?m=1. Accessed on: Mar. 2018. 